\title{
Spectroscopic Properties of Polycyclic Aromatic Hydrocarbons: Effect of Solvent Polarity on the Fluorescence Emission Behavior of Select Fluoranthene, Fluorenochrysene, Indenochrysene, and Indenopyrene Derivatives
}

\author{
SHERYL A. TUCKER, WILLIAM E. ACREE, JR., ${ }^{*}$ BONGSUP P. CHO, RONALD G. \\ HARVEY, and JOHN C. FETZER \\ Department of Chemistry, University of North Texas, Denton, Texas 76203-5068 (S.A.T., W.E.A.); Ben May Institute, University \\ of Chicago, Chicago, Illinois 60637 (B.P.C., R.G.H.); and Chevron Research and Technology Center, Richmond, California 94802- \\ 0627 (J.C.F.)
}

\begin{abstract}
Fluorescence emission behavior is reported for benz[def]indeno$[1,2,3 \mathrm{hi}]$ chrysene, fluoreno[ $2,3,4,9 \mathrm{defg}]$ chrysene, benz[def]indeno$[1,2,3 q$ r $]$ chrysene, dibenzo[a,e]fluoranthene, indeno[1,2,3cd]pyrene, naphtho[1,2b]fluoranthene, benzo[b]fluoranthene, fluoranthene, benzo[ghi]fluoranthene, naphtho[2,1a]fluoranthene, naphtho[2,3b]fluoranthene, benzo[k]fluoranthene, and benzo[j]fluoranthene dissolved in organic nonelectrolyte solvents of varying polarity. Results of these measurements are used to classify the various solutes as either probe or nonprobe molecules, depending upon whether measured emission intensity ratios vary systematically with solvent polarity. Also discussed are primary and secondary inner-filtering artifacts associated with selective quenching agents used to help identify/analyze polycyclic aromatic hydrocarbons (PAHs) in unknown mixtures. Inner-filtering artifacts are illustrated by examining fluorescence emission intensities of 13 "nonalternant" PAHs at different nitromethane concentrations and solution absorbances.
\end{abstract}

Index Headings: Fluorescence; Spectroscopic techniques.

\section{INTRODUCTION}

This paper continues a systematic, experimental investigation of the effect that solvent polarity has on the photophysical properties of large, multi-ring polycyclic aromatic compounds in order to identify probe molecules for future applications. The emission spectrum of a polycyclic aromatic hydrocarbon (PAH) monomer consists of several major vibronic bands labeled I, II, etc., in progressive order. Previous measurements ${ }^{1-7}$ revealed that pyrene, benzo[ghi]perylene, ovalene, coronene, benzo[a]coronene, naphtho[2,3a]coronene, benzo[e]pyrene, naphtho[8,1,2abc]coronene, dinaphtho[8,1,2abc;2', $1^{\prime}, 8^{\prime}$ $\mathrm{klm}$ ] coronene, dibenzo[def,p]chrysene, phenanthro[5,4,3,2efghi]perylene, and benzo[rst]pentaphene exhibit selective emission intensity enhancement of vibronic band I relative to band III (or band II or IV) in polar solvents. The ratio of emission intensities serves as a quantitative measure of solvent polarity and structure. Interestingly, only 17 of the 45 PAH6 benzenoids studied to date behave in this fashion. Various emission intensity ratios of perylene, dibenzo[bc,ef]coronene, benzo[a]pyrene, benzo[pqr] naphtho[ $8,1,2 \mathrm{bcd}]$ perylene, di-

Received 11 June 1991.

* Author to whom correspondence should be sent. benzo[fg,ij]pentaphene, and several other PAHs remained essentially constant, irrespective of solvent polarity.

Solvent-induced fluorescence spectral changes can be rationalized qualitatively in a relatively straightforward manner. Excitation promotes the PAH solute from a ground state of low dipole moment to one of the vibrational levels of the first electronic excited state, $S_{V}^{*}$, with an accompanying electron distribution in the surrounding solvent molecules. Insufficient time exists, however, for solvational-sphere molecules to physically reorient with the new PAH dipole moment. Relaxation from the vibrationally excited $S_{V}^{*}$ level to the excited $S_{o}^{*}$ level occurs whenever solvent molecules rotationally reorient to a more stable dipole configuration during the excited state's lifetime. Emission of the fluorescence photon returns both the PAH molecule to the ground $S_{V}$ state and solvational molecules to their initial electronic configuration. Subsequent rotation of solvent molecules to the ground-state dipole orientation restores the system to its original state. Transition probabilities and energy separations between the different energy levels vary with each solute-solvent pair, and give rise to observed intensity ratio changes and emission wavelength shifts. ${ }^{8,9}$

Solvent-induced fluorescence changes provide valuable information regarding the micro-environment immediately surrounding the PAH solute probe. These effects can be extremely undesirable from a quantitative analysis standpoint. PAH identification and quantification requires accurate fluorescence emission intensity measurements and availability of a large spectral data file for comparing the unknown's spectrum against PAH standards. Kalman filtering and Gaussian or other curvefitting techniques, ${ }^{10-13}$ along with the selective photochemical quenching agents such as nitromethane ${ }^{14-18}$ and 1,2,4-trimethoxybenzene, ${ }^{18}$ may be needed to uncouple overlapping spectra if more than one fluorescent species is present. To prevent misidentification, the data file should include both polar and nonpolar solvents since electronic interactions between a solvent dipole and an excited PAH solute can lead to spectral distortions, wavelength shifts, and/or intensity ratio variations.

Now that studies on PAH6 benzenoids are nearly complete, it is time to expand our measurements to include other subclasses of aromatic compounds such 

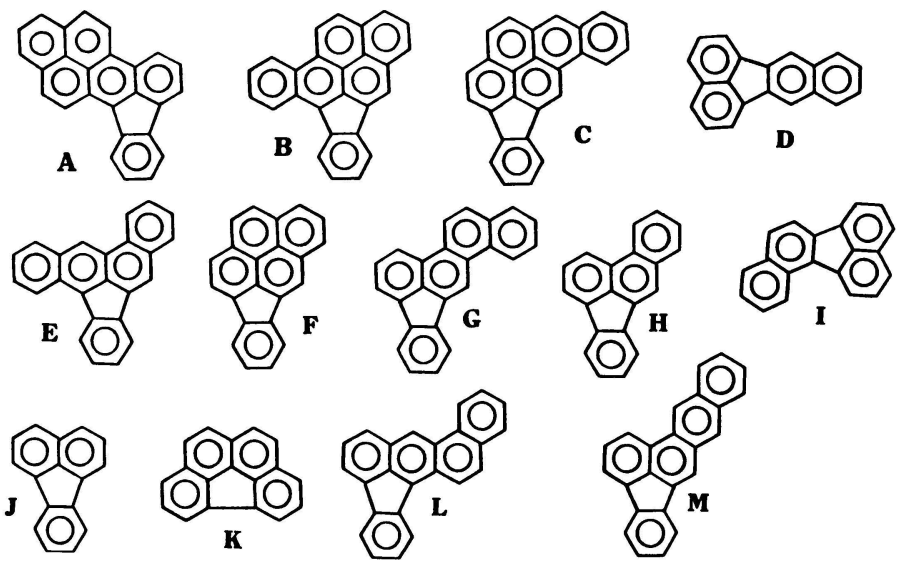

FIG. 1. Molecular structures of nonalternant PAH compounds: (A) benz[def]indeno[1,2,3hi]chrysene; (B) fluoreno[2,3,4,9defg]chrysene; (C) benz[def]indeno[1,2,3qr]chrysene; (D) benzo[k]fluoranthene; (E) dibenzo[a,e]fluoranthene; (F) indeno[1,2,3cd]pyrene; (G) naphtho[1,2b]fluoranthene; $(\mathbf{H})$ benzo[b]fluoranthene; $(\mathrm{I})$ benzo[j]fluoanthene; (J) fluoranthene; (K) benzo[ghi]fluoranthene; $(\mathbf{L})$ naphtho$[2,1 \mathrm{a}]$ fluoranthene; and $(\mathbf{M})$ naphtho[2,3b]fluoranthene. Alternate chemical names based upon IUPAC nomenclature are given in Reference 19.

as "nonalternant" PAHs. For this reason we report the fluorescence behavior of benz[def]indeno[1,2,3hi]chrysene, fluoreno[2,3,4,9defg]chrysene, benz[def]indeno[ $[1,2,3 \mathrm{qr}]$ chrysene, dibenzo[a,e]fluoranthene, indeno[ $1,2,3 \mathrm{~cd}]$ pyrene, naphtho[ $1,2 \mathrm{~b}]$ fluoranthene, benzo[b]fluoranthene,fluoranthene, benzo[ghi]fluoranthene, naphtho[2,1a]fluoranthene, naphtho[2,3b]fluoranthene, benzo[k]fluoranthene, and benzo[j]fluoranthene(see Fig. 1 for molecular structures) dissolved in nonelectrolyte organic solvents of varying polarity. Unlike the 45 PAH6 benzenoids studied thus far, these thirteen aromatic molecules contain a single five-membered cyclopentadiene ring. Also included in the present study are preliminary observations concerning chemical and instrumental artifacts associated with the use of nitromethane as a selective quenching agent. On the basis of limited fluorescence measurements on perylene, dibenzo[b,k]chrysene, dibenzo[h,rst]pentaphene, naphtho$[1,2 \mathrm{~b}]$ fluoranthene, indeno[1,2,3cd]pyrene, and 10.11(peri-naphthylene)-fluoranthene, Blümer and Zander ${ }^{15}$ noted that nitromethane and nitrobenzene selectively quenched fluorescence emission of only the so-called "alternant" polycyclic aromatic hydrocarbons. Emission intensities of the three nonalternant PAHs (e.g., naphtho[1,2b]fluoranthene, indeno[1,2,3cd]pyrene, and 10.11(peri-naphthylene)-fluoranthene) remain unchanged. Neglect of primary and secondary inner-filtering artifacts can lead to misidentification of PAH type, particularly if the quenching agent absorbs an appreciable amount of excitation and/or emission radiation, as is often the case with nitromethane.

\section{MATERIALS AND METHODS}

Fluoranthene, benzo[j]fluoranthene, benzo[k]fluoranthene, benzo[b]fluoranthene, and benzo[ghi]fluoranthene were purchased commercially from the Bureau of Community Reference in Brussels, Belgium. The remaining PAHs were synthesized and purified by proce-

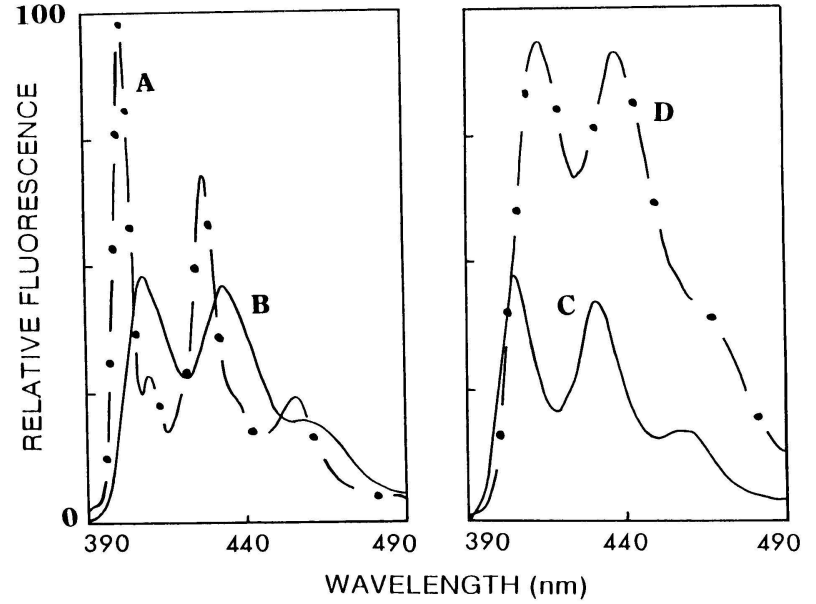

FIG. 2. Fluorescence emission spectra of benzo[k]fluoranthene dissolved in $[A(-\cdot-\cdot-)] n$-hexadecane; $[B(-)]$ dichloromethane; $(C(-)]$ butyl acetate; and $[D(-\cdot \cdot-)]$ dimethyl sulfoxide. In butyl acetate emission bands occur at 405,430 , and $458 \mathrm{~nm}$.

dures described in the literature. ${ }^{19}$ Stock solutions were prepared by dissolving the solutes in dichloromethane. Small aliquots of the stock solutions were transferred into test tubes, allowed to evaporate, and diluted with the solvent of interest. Final solute concentrations were sufficiently dilute to minimize inner-filtering artifacts. Solvents were of HPLC, spectroquality, or AR grade, purchased commercially from either Aldrich or Fisher Scientific, and the resulting solutions were optically dilute (absorbances $\mathrm{cm}^{-1} \leq 0.01$ ) at all wavelengths investigated, except for the quenching study, where the nitromethane concentration was continually increased to allow examination of inner-filtering artifacts.

Absorption spectra were recorded on a Bausch and Lomb Spectronic 2000 and a Hewlett-Packard 8450A photodiode array spectrophotometer in the usual manner with a $1-\mathrm{cm}^{2}$ quartz cuvette. The fluorescence spectra were run on a Shimadzu RF-5000U spectrofluorometer with the detector set at high sensitivity. Solutions were excited at $300 \mathrm{~nm}$ (fluoranthene); $406 \mathrm{~nm}$ (benz[def]-

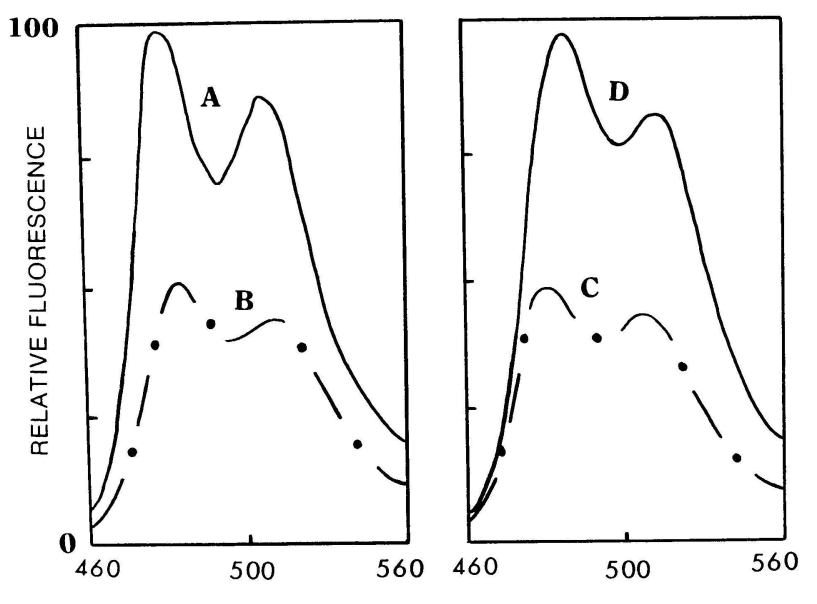

WAVELENGTH $(\mathbf{n m})$

FIG. 3. Fluorescence emission spectra of benz[def]indeno$[1,2,3 \mathrm{qr}]$ chrysene dissolved in $[A(-)] n$-hexadecane; $[B(-\cdot-\cdot-)]$ dichloromethane; $[C(-\cdot \cdot-)]$ butyl acetate; and $[D(-)]$ dimethyl sulfoxide. In butyl acetate emission bands occur at 486 and $517 \mathrm{~nm}$. 


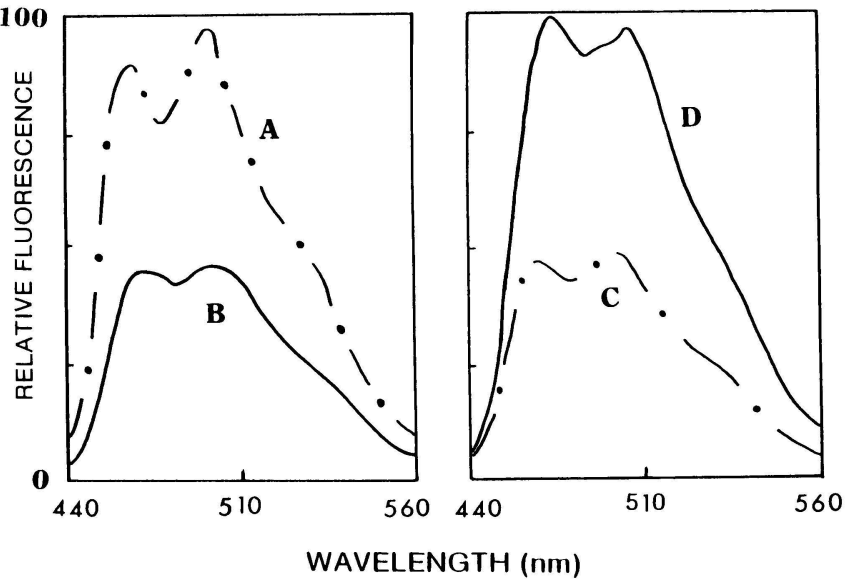

FIG. 4. Fluorescence emission spectra of naphtho[2,1a]fluoranthene dissolved in $[A(-\cdot \cdot-)] n$-hexadecane; $[B(-)]$ dichloromethane; $[C(-\cdot-\cdot)]$ butyl acetate; and $[D(-)]$ dimethyl sulfoxide. In butyl acetate emission bands occur at 464 and $491 \mathrm{~nm}$.

indeno[1,2,3hi]chrysene); $408 \mathrm{~nm}$ (benz[def]indeno[1,2,3qr ]chrysene); $315 \mathrm{~nm}$ (fluoreno[2,3,4,9defg]chrysene); 300 and $340 \mathrm{~nm}$ (indeno[1,2,3cd]pyrene); 340 $\mathrm{nm}$ (benzo[ghi]fluoranthene); $315 \mathrm{~nm}$ (benzo[j]fluoranthene); $346 \mathrm{~nm}$ (benzo[b]fluoranthene); $306 \mathrm{~nm}$ (ben$\mathrm{zo}[\mathrm{k}]$ fluoranthene); $316 \mathrm{~nm}$ (naphtho[2,3b]fluoranthene); $350 \mathrm{~nm}$ (naphtho[1,2b]fluoranthene); $390 \mathrm{~nm}$ (dibenzo[a,e]fluoranthene); and $400 \mathrm{~nm}$ (naphtho[2,1a]fluoranthene) in a quartz $1-\mathrm{cm}^{2}$ cuvette. All fluorescence data were accumulated at $19^{\circ} \mathrm{C}$, ambient room temperature, with excitation and emission slit width settings of $15 \mathrm{~nm}$ and $3 \mathrm{~nm}$, respectively. The PAH fluorescence spectra, depicted in Figs. 2-7, represent a single scan which was then solvent blank corrected and verified by repetitive measurements.

\section{RESULTS AND DISCUSSION}

Representative fluorescence emission spectra of benzo[k]fluoranthene, benz [def] indeno[ $1,2,3 \mathrm{qr}]$ chrysene, naphtho[2,1a]fluoranthene, naphtho[2,3b]fluoranthene,

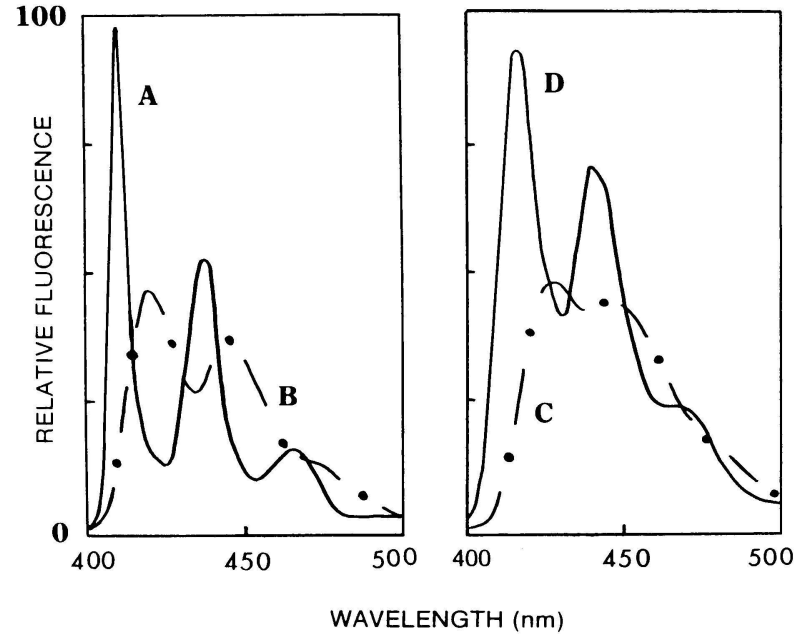

FIG. 5. Fluorescence emission spectra of naphtho[2,3b]fluoranthene dissolved in $[A(-)] n$-hexadecane; $[B(-\cdot-\cdot)]$ dichloromethane; [C (-.-.-)] butyl acetate; and [D(-)] dimethyl sulfoxide. In butyl acetate emission bands occur at 416, 442, and $469 \mathrm{~nm}$.

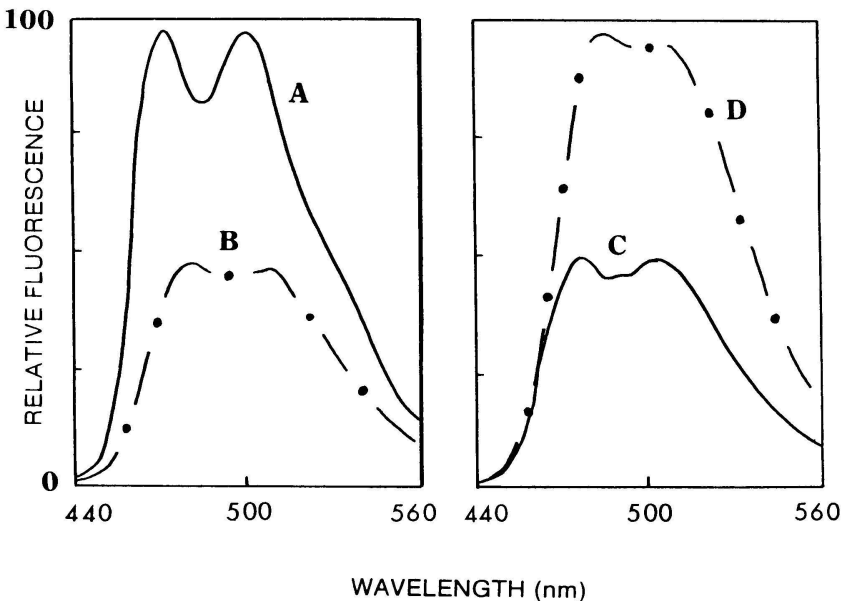

FIG. 6. Fluorescence emission spectra of dibenzo[a,e]fluoranthene dissolved in $[A(-)] n$-hexadecane; $[B(-\cdot-\cdot)]$ dichloromethane; [C (-) butyl acetate]; and [D(-.-.-)] dimethyl sulfoxide. In butyl acetate emission bands occur at 477 and $502 \mathrm{~nm}$.

dibenzo[a,e]fluoranthene, and benz[def]indeno[1,2,3hi]chrysene dissolved in $n$-hexadecane, butyl acetate, dichloromethane, and dimethyl sulfoxide are shown in Figs. $2-7$. Nonelectrolyte solvents were judiciously selected so as to encompass the entire range of solvent polarity, from the nonpolar $n$-hexadecane hydrocarbon to the moderately polar butyl acetate and dichloromethane to the very polar dimethyl sulfoxide. Examination of the spectral data reveals that benzo[k]fluoranthene, benzo[ghi]fluoranthene, naphtho[2,3b]fluoranthene, and indeno[1,2,3cd]pyrene do exhibit three- and/or four-band emission fine structure similar to that observed for many of the PAH6 benzenoids studied previously. ${ }^{1-7}$ Only ben$\mathrm{zo}[\mathrm{k}]$ fluoranthene and naphtho[2,3b]fluoranthene showed probe character, however, as evidenced by systematic variation of emission intensity ratios with solvent polarity. Calculated emission intensity band ratios for benzo[k]fluoranthene (BFA; I/II) and naphtho$[2,3 \mathrm{~b}]$ fluoranthene $(\mathrm{NFA} ; \mathrm{I} / \mathrm{II})$ ranged from $\mathrm{BFA}=1.48$ and $\mathrm{NFA}=1.88$ in cyclohexane to $\mathrm{BFA}=1.00$ and $\mathrm{NFA}$

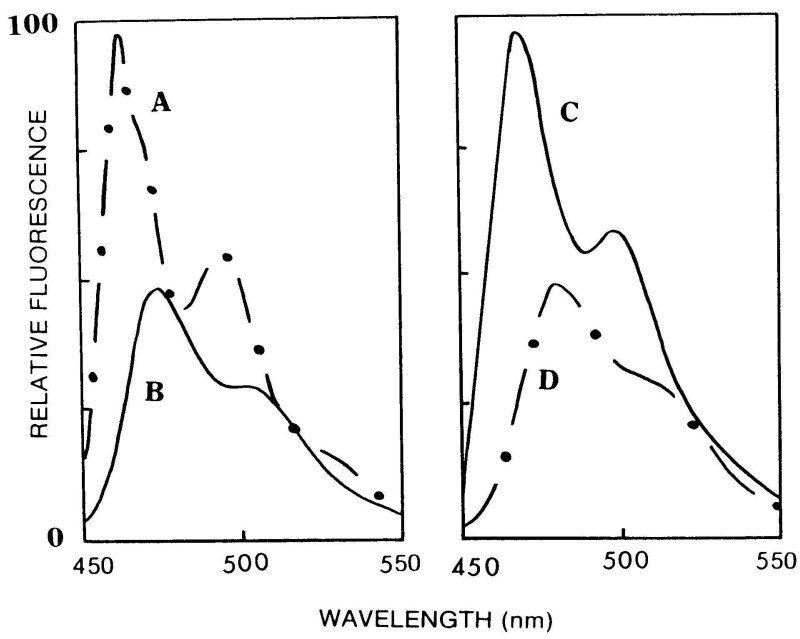

FIG. 7. Fluorescence emission spectra of benz[def]indeno$[1,2,3$ hi $]$ chrysene dissolved in $[A(-\cdot-\cdot-)] n$-hexadecane; $[B(-)]$ dichloromethane; $[C(-)]$ butyl acetate; and $[D(-\cdots)]$ dimethyl sulfoxide. In butyl acetate emission bands occur at 469 and $498 \mathrm{~nm}$. 
TABLE I. Ratios of fluorescence emission intensities for ben$z o[k]$ fluoranthene and naphtho[2,3b]fluoranthene dissolved in select organic solvents.

\begin{tabular}{lccc}
\hline \multicolumn{1}{c}{ Solvent } & Py $^{\mathrm{a}}$ & BFA $^{\mathrm{b}}$ & NFA $^{\mathrm{c}}$ \\
\hline Cyclohexane & 0.58 & 1.48 & 1.88 \\
2,2,4-Trimethylpentane & 0.59 & 1.46 & 1.87 \\
n-Hexadecane & 0.60 & 1.43 & 1.84 \\
Carbon tetrachloride & $\ldots$ & 1.31 & 1.63 \\
Dibutyl ether & 0.84 & 1.24 & 1.44 \\
Benzene & 1.05 & 1.13 & 1.37 \\
2-Propanol & 1.09 & 1.10 & 1.24 \\
Chloroform & 1.25 & 1.10 & 1.32 \\
Butyl acetate & 1.35 & 1.11 & 1.28 \\
Methanol & 1.35 & 1.08 & 1.14 \\
Dichloromethane & 1.35 & 1.04 & 1.25 \\
Acetonitrile & 1.79 & 1.04 & 1.12 \\
N,N-Dimethyl formamide & 1.81 & 1.00 & 1.18 \\
Dimethyl sulfoxide & 1.95 & 1.00 & 1.09 \\
Dynamic range & 1.37 & 0.48 & 0.79 \\
\hline
\end{tabular}

a Experimental Py values are from Dong and Winnik ${ }^{20}$ and are based on the fluorescence emission properties of pyrene.

${ }^{\mathrm{b}}$ Defined as the ratio of band I (at $402-413 \mathrm{~nm}$ )/band II (at $427-437$ nm).

Defined as the ratio of band I (at $410-427 \mathrm{~nm}$ )/band II (at 436-448 nm).

$=1.09$ in dimethyl sulfoxide. Actual numerical values for the 14 solvents examined are tabulated in Table I. Estimated uncertainties in the measured intensity ratios are believed to be on the order of \pm 0.04 (or less) on the basis of replicate determinations. As an example, measured values for butyl acetate over a five-day period of $\mathrm{BFA}=1.11,1.14,1.11,1.09$, and 1.10 indicate very good reproducibility. Although benzo[k]fluoranthene and naphtho[2,3b]fluoranthene do show modest probe character, their respective dynamic ranges of 0.48 and 0.79 are significantly smaller than those of pyrene (1.37), benzo[ghi]perylene (0.98), and ovalene (2.08)..$^{1,7,20}$ Better solvent discrimination is permitted by these latter three PAH6 benzenoids. Furthermore, benzo[ghi]perylene and ovalene have excitation wavelengths into the visible region, and are thus less prone to inner-filtering artifacts arising from solvent absorption of excitation radiation. Presently there appears to be no compelling reason for us to ever recommend using the two fluoranthene derivatives in place of pyrene, benzo[ghi]perylene, and ovalene in solvent polarity determinations. The remaining compounds studied possessed either one broad, fairly unsymmetrical emission band (likely two or more unresolvable bands) or two poorly resolved emission bands in the 350-600 $\mathrm{nm}$ spectral region, except for fluoranthene and indeno[1,2,3cd]pyrene, which also had several very weak emission peaks of nearly constant intensity ratio.

From an analytical perspective, identification and quantification of unknown PAH mixtures require accurate fluorescence emission intensity measurements and availability of a large spectral data file for comparing the unknown's spectrum against PAH standards. Unfortunately, many PAHs emit in approximately the same spectral regions, thus hindering identification in the case of multicomponent mixtures. Kalman filtering and Gaussian or other curve-fitting techniques theoretically allow uncoupling of overlapping spectra. Such methods become less reliable, however, as the number of mixture components increases. High-performance liquid chro-

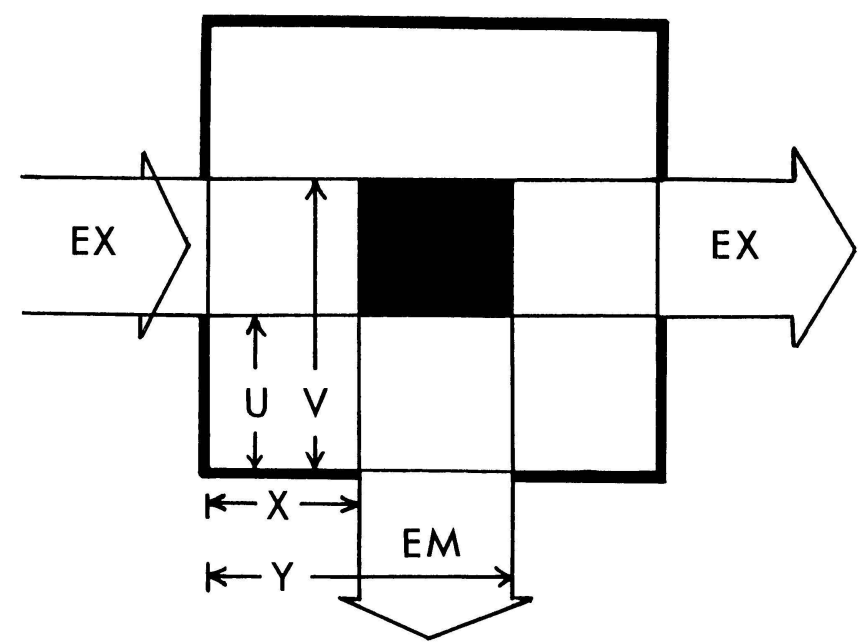

FIG. 8. Typical cell configuration for right-angle fluorometry. Window parameters $(x, y)$ and $(u, v)$ are determined by masking apertures or some other limiting aperture in emission and excitation beam, respectively.

matographic (HPLC) separation prior to fluorometric analysis affords a viable alternative, but again the method is extremely time-consuming whenever large numbers of isomeric PAHs are present. Blümer and Zander ${ }^{15}$ recommended that nitromethane and/or nitrobenzene could be added to an aqueous-acetonitrile (20:80 by volume) binary mobile phase to selectively suppress fluorescence signals of alternant PAHs. Emission intensities of nonalternant PAHs would remain unchanged.

Utilization of selective quenching agents can significantly simplify observed emission spectra. To prevent misidentification, experimentally determined spectra must be free of chemical and instrumental artifacts that might unexpectedly reduce emission intensities. Innerfiltering is a major problem associated with obtaining correct fluorescence data, which assumes that the sample is optically dilute $\left(A \mathrm{~cm}^{-1} \leq 0.01\right)$ at all analytical wavelengths. Most commercial instruments employ right-angle fluorometry, which reduces stray radiation by placing the emission detector at $90^{\circ}$ with respect to the incoming excitation beam (see Fig. 8). Only fluorescence emission originating from the center interrogation zone of the sample cell is actually collected. Attenuation of the excitation beam before reaching the region viewed by the fluorescence detection optics (pre-filter region) and through the interrogation volume element is denoted as primary inner-filtering. The correction factor, $f_{\text {prim }}$, for primary inner-filtering is given by the following expression $^{21-23}$

$$
f_{\text {prim }}=\frac{F^{\text {corr }}}{F^{o b s}}=\frac{2.303 A(y-x)}{10^{-A_{x}}-10^{-A_{y}}}
$$

where $F^{c o r r}$ and $F^{o b s}$ refer to the corrected and observed fluorescence emission signal, respectively; $A$ is the absorbance per centimeter of pathlength at the excitation wavelength; and $x$ and $y$ denote distances from the boundaries of the interrogation zone to the excitation plane, as shown in Fig. 8. Equation 1 strictly applies to monochromatic light, which from an experimental standpoint is never achievable, even with the finest spectrofluorometers having small spectral bandpasses. Yappert 
and Ingle ${ }^{23}$ derived a more rigorous mathematical treatment for non-monochromatic excitation and emission beams.

Primary inner-filtering can often be ignored in PAH solvent polarity experiments requiring determination of intensity ratios as the excitation wavelength remains constant (i.e., $A$ in Eq. 1 remains constant). Emission intensities of both bands are thus affected by the same relative amount. Selective quenching studies are another matter, however, as absorption of the excitation beam by the quenching agent would reduce emission intensities of every fluorophore having the given excitation wavelength. In the case of nitromethane, inner-filtering would reduce emission intensities of both alternant and nonalternant PAHs by the same relative amount. For determination of whether selective quenching really occurred, observed emission intensities, $F^{\text {obs }}$, must be multiplied by the inner-filtering correction factor, $f_{\text {prim }}$, in order to eliminate the undesired effects from this chemical artifact. Failure to correct the observed intensities may lead to erroneous conclusions concerning PAH identification (alternant vs. nonalternant), particularly if excitation wavelengths of $300 \mathrm{~nm}$ or less are employed. Many PAHs have excitation wavelengths in the 300-320 $\mathrm{nm}$ spectral region, and a few drops of nitromethane (or nitrobenzene) give solutions of appreciable absorbances.

Secondary inner-filtering results from absorption of large quantities of emitted fluorescence, and the correction factor, $f_{s e c}$,

$$
f_{\text {sec }}=\frac{F^{\text {corr }}}{F^{o b s}}=\frac{(v-u)(1 / b) \ln T}{T_{\text {at } v / b}-T_{\text {at } u / b}}
$$

contains $^{22}$ the sample transmittance $(T)$ across the entire cell pathlength $(b)$ at the emission wavelength. Transmittances at the two interrogation zone boundaries, $T_{\text {at } v / b}$ and $T_{\text {at } u / b}$, are calculated from the measured absorbance at the emission wavelength via the BeersLambert law. Remember that $v / b$ and $u / b$ now serve as the new cell pathlengths.

For PAH solvent polarity determinations, secondary inner-filtering is a primary concern if the solution preferentially absorbs one of the PAH emission bands, thus leading to different transmittances ( $T$ values in Eq. 2) at the various emission wavelengths and erroneously low intensity ratios. Selective quenching experiments are not generally affected by secondary inner-filtering artifacts. PAH emission bands appear in the $370-500 \mathrm{~nm}$ spectral region, where nitromethane's absorbance is greatly diminished. Readers are reminded that only a few drops of quenching agent are used in this type of experiment. by

The corrected fluorescence emission intensity is given

$$
F^{c o r r}=f_{\text {prim }} f_{\text {sec }} F^{\text {obs }}
$$

assuming that primary and secondary inner-filtering are independent processes. As a general rule of thumb, innerfiltering corrections work well for $f_{\text {prim }}$ and $f_{\text {sec }}$ values of less than three. Calculation of each correction factor requires a priori knowledge of interrogation zone volume and dimensions. Realizing that most instrument manufacturers rarely supply information regarding sample compartment aperture slit widths, particularly for the less expensive spectrofluorometers and fluorescence de-
TABLE II. Numerical values of primary and secondary inner-filtering correction factors at various solution absorbances for $\boldsymbol{x}=\boldsymbol{u}=0.45 \mathrm{~cm}$ and $y$ and $v=0.55 \mathrm{~cm}$.

\begin{tabular}{ccc}
\hline$A \mathrm{~cm}^{-1}$ & $f_{\text {prim }}$ & $f_{\text {sec }}$ \\
\hline 0.000 & 1.000 & 1.000 \\
0.050 & 1.059 & 1.059 \\
0.100 & 1.122 & 1.122 \\
0.150 & 1.189 & 1.188 \\
0.200 & 1.259 & 1.259 \\
0.250 & 1.334 & 1.333 \\
0.300 & 1.413 & 1.412 \\
0.350 & 1.496 & 1.496 \\
0.400 & 1.585 & 1.584 \\
0.450 & 1.678 & 1.678 \\
0.500 & 1.778 & 1.777 \\
0.550 & 1.883 & 1.882 \\
0.600 & 1.994 & 1.994 \\
0.650 & 2.112 & 2.112 \\
0.700 & 2.237 & 2.236 \\
0.750 & 2.369 & 2.368 \\
0.800 & 2.509 & 2.508 \\
0.850 & 2.657 & 2.656 \\
0.900 & 2.814 & 2.813 \\
0.950 & 2.980 & 2.979 \\
1.000 & 3.156 & 3.155 \\
1.050 & 3.342 & 3.342 \\
1.110 & 3.539 & 3.359 \\
1.150 & 3.748 & 3.747 \\
1.200 & 3.969 & 3.968 \\
1.250 & 4.203 & 4.202 \\
1.300 & 4.451 & 4.450 \\
1.350 & 4.713 & 4.713 \\
1.400 & 4.991 & 4.990 \\
\hline & &
\end{tabular}

tectors used in HPLC, we have elected to base $f_{\text {prim }}$ and $f_{s e c}$ computations upon assumed values of $x, y, u$, and $v$. Table II lists numerical values of $f_{\text {prim }}$ and $f_{\text {sec }}$ as a function of solution absorbance for $x=u=0.45 \mathrm{~cm}$ and $y=v=$ $0.55 \mathrm{~cm}$.

Figure 9 depicts the fluorescence emission spectra of

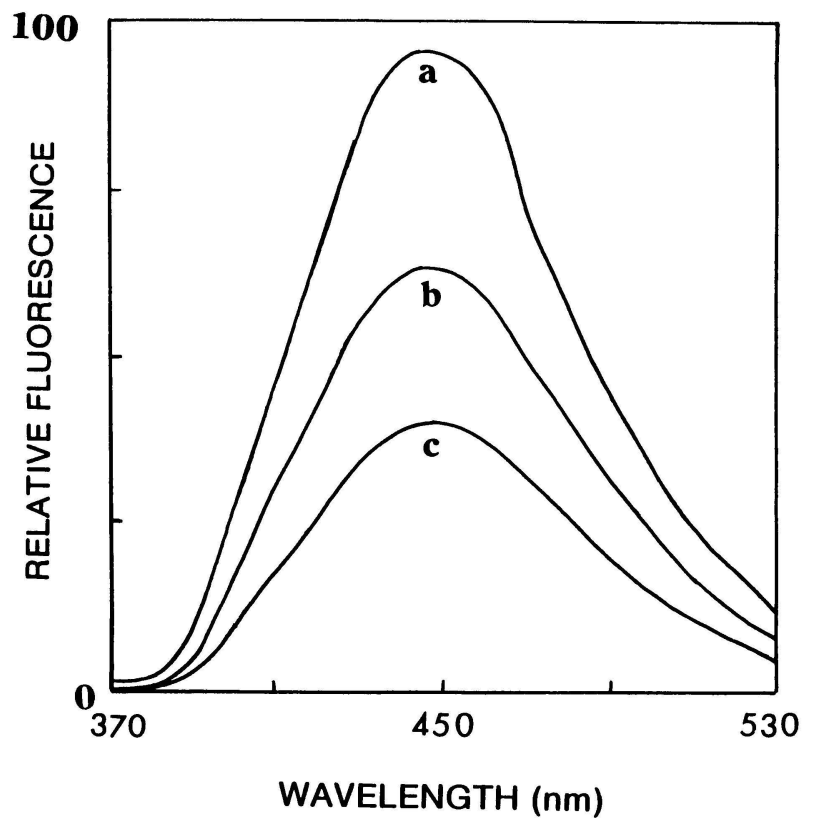

FIG. 9. Effect of nitromethane concentration on the fluorescence emission behavior of benzo[b]fluoranthene dissolved in a binary aqueousacetonitrile ( $20: 80$ by volume) solvent mixture. Curves $a-c$ correspond to 0,2 , and 5 small drops of neat nitromethane to approximately $5 \mathrm{~mL}$ of solution. 
TABLE III. Effect of nitromethane concentration on the fluorescence emission intensities of select nonalternant polycyclic aromatic hydrocarbons.

\begin{tabular}{|c|c|c|c|c|}
\hline PAH solute & $F^{o b s^{a}}$ & $A \mathrm{~cm}^{-1 \mathrm{~b}}$ & $f_{\text {prim }}{ }^{\mathrm{c}}$ & $F^{\text {corr }}$ \\
\hline \multirow{6}{*}{$\begin{array}{l}\text { Benzo[b]fluoranthene } \\
\text { (emission: } 446 \mathrm{~nm} \text { ) }\end{array}$} & 586.4 & 0.016 & 1.02 & 598.2 \\
\hline & 475.8 & 0.167 & 1.22 & 580.2 \\
\hline & 410.3 & 0.292 & 1.40 & 574.4 \\
\hline & 342.7 & 0.432 & 1.64 & 562.1 \\
\hline & 297.7 & 0.558 & 1.90 & 565.6 \\
\hline & 230.1 & 0.775 & 2.45 & 563.7 \\
\hline \multirow{6}{*}{$\begin{array}{l}\text { Benz [def]indeno }[1,2,3 \text { hi }] \text { chrysene } \\
\text { (emission: } 476 \mathrm{~nm} \text { ) }\end{array}$} & 432.8 & 0.005 & 1.01 & 437.2 \\
\hline & 457.4 & 0.000 & 1.00 & 457.4 \\
\hline & 461.5 & 0.000 & 1.00 & 461.5 \\
\hline & 457.4 & 0.000 & 1.00 & 457.4 \\
\hline & 443.1 & 0.000 & 1.00 & 443.1 \\
\hline & 443.1 & 0.001 & 1.00 & 443.1 \\
\hline \multirow{2}{*}{$\begin{array}{l}\text { Fluoranthene } \\
\text { (emission: } 372 \mathrm{~nm})\end{array}$} & 143.0 & 0.044 & 1.05 & 150.2 \\
\hline & Zero & 0.676 & 2.176 & Zero \\
\hline \multirow{3}{*}{$\begin{array}{l}\text { Benzo[j]fluoranthene } \\
\text { (emission: } 508 \mathrm{~nm})\end{array}$} & 217.8 & 0.013 & 1.02 & 222.2 \\
\hline & 146.1 & 0.384 & 1.55 & 226.5 \\
\hline & 102.2 & 0.714 & 2.26 & 231.0 \\
\hline \multirow{4}{*}{$\begin{array}{l}\text { Benz[def]indeno[1,2,3q]chrysene } \\
\text { (emission: } 489 \mathrm{~nm})\end{array}$} & 656.1 & 0.018 & 1.02 & 669.2 \\
\hline & 664.3 & 0.017 & 1.02 & 677.5 \\
\hline & 639.7 & 0.018 & 1.02 & 652.5 \\
\hline & 635.6 & 0.017 & 1.02 & 648.3 \\
\hline \multirow{4}{*}{$\begin{array}{l}\text { Indeno[1,2,3cd]pyrene } \\
\text { (emission: } 474 \mathrm{~nm})\end{array}$} & 185.0 & 0.011 & 1.01 & 187.4 \\
\hline & 153.8 & 0.245 & 1.33 & 203.9 \\
\hline & 123.1 & 0.502 & 1.78 & 219.3 \\
\hline & 95.1 & 0.739 & 2.34 & 222.5 \\
\hline \multirow{3}{*}{$\begin{array}{l}\text { Benzo[k]fluoranthene } \\
\text { (emission: } 408 \mathrm{~nm})\end{array}$} & 840.4 & 0.000 & 1.00 & 840.4 \\
\hline & 299.7 & 0.541 & 1.86 & 557.5 \\
\hline & 131.7 & 1.026 & 3.27 & 430.9 \\
\hline \multirow{3}{*}{$\begin{array}{l}\text { Naphtho[2,3b]fluoranthene } \\
\text { (emission: } 422 \mathrm{~nm} \text { ) }\end{array}$} & 979.6 & 0.002 & 1.00 & 979.6 \\
\hline & 500.4 & 0.336 & 1.47 & 736.7 \\
\hline & 178.9 & 0.925 & 2.90 & 518.0 \\
\hline \multirow{4}{*}{$\begin{array}{l}\text { Naphtho[2,1a]fluoranthene } \\
\text { (emission: } 466 \mathrm{~nm} \text { ) }\end{array}$} & 512.7 & 0.002 & 1.00 & 512.7 \\
\hline & 492.2 & 0.001 & 1.00 & 492.2 \\
\hline & 488.1 & 0.001 & 1.00 & 488.1 \\
\hline & 490.2 & 0.001 & 1.00 & 490.2 \\
\hline \multirow{3}{*}{$\begin{array}{l}\text { Benzo[ghi]fluoranthene } \\
\text { (emission: } 447 \mathrm{~nm} \text { ) }\end{array}$} & 996.0 & 0.066 & 1.08 & 1075.7 \\
\hline & 877.2 & 0.186 & 1.24 & 1087.8 \\
\hline & 762.6 & 0.310 & 1.43 & 1090.5 \\
\hline \multirow{3}{*}{$\begin{array}{l}\text { Fluoreno[2,3,4,9defg]chrysene } \\
\text { (emission: } 478 \mathrm{~nm} \text { ) }\end{array}$} & 52.4 & 0.033 & 1.04 & 54.5 \\
\hline & 40.6 & 0.392 & 1.57 & 63.8 \\
\hline & 28.6 & 0.737 & 2.34 & 66.9 \\
\hline \multirow{4}{*}{$\begin{array}{l}\text { Dibenzo[a,e]fluoranthene } \\
\text { (emission: } 482 \mathrm{~nm})\end{array}$} & 165.6 & 0.038 & 1.05 & 173.8 \\
\hline & 171.7 & 0.026 & 1.04 & 178.6 \\
\hline & 182.9 & 0.022 & 1.02 & 186.6 \\
\hline & 186.1 & 0.016 & 1.02 & 189.8 \\
\hline \multirow{6}{*}{$\begin{array}{l}\text { Naphtho[1,2b]fluoranthene } \\
\text { (emission: } 438 \mathrm{~nm} \text { ) }\end{array}$} & 334.5 & 0.000 & 1.00 & 334.5 \\
\hline & 292.5 & 0.062 & 1.07 & 313.0 \\
\hline & 257.7 & 0.134 & 1.16 & 299.0 \\
\hline & 228.0 & 0.206 & 1.27 & 289.6 \\
\hline & 201.4 & 0.284 & 1.38 & 277.9 \\
\hline & 175.8 & 0.360 & 1.51 & 265.5 \\
\hline
\end{tabular}

a After the initial intensity reading, each successive value corresponds to addition of one drop of nitromethane.

${ }^{b}$ Absorbance of the solution measured at the excitation wavelength of the PAH under investigation.

' Primary inner-filtering correction factors based upon $x=u=0.45 \mathrm{~cm}$ and $y=v=0.55 \mathrm{~cm}$.

benzo[b]fluoranthene as a function of nitromethane concentration. Solution absorbances for curves $a-c$ are $\sim A$ $\mathrm{cm}^{-1}=0.016,0.292$, and 0.775 , respectively. Numerical values of $F^{o b s}$ and $A \mathrm{~cm}^{-1}$ for benzo[b]fluoranthene are summarized in Table III, along with representative experimental data for the remaining 12 nonalternant PAHs studied. Unfortunately, solutions $b$ and $c$ are no longer optically dilute at benzo[b]fluoranthene's excitation wavelength. A significant fraction of the observed emission intensity reduction results from primary inner-fil- tering. Multiplication of the observed fluorescence intensity by $f_{\text {prim }}$ increases the value to $F^{\text {corr }} \approx 570$, which is approximately equal to the initial emission intensity before addition of nitromethane. Our studies clearly show that nitromethane does not quench the fluorescence emission of benzo[b]fluoranthene. Neglect of primary inner-filtering would lead one to the erroneous conclusion that this particular PAH was an exception to the selective quenching observation previously noted by Blümer and Zander. ${ }^{15}$ Recall that nitromethane is suppose to selectively quench fluorescence emission intensities of alternant PAHs as opposed to nonalternant PAHs. The chemical literature does contain an earlier report that benzo[b]fluoranthene was one of three exceptions. ${ }^{16}$ The authors' experimental procedure was only briefly described, and we failed to see how primary inner-filtering was avoided (as claimed) if the sample was irradiated at the optimum excitation wavelength.

Careful examination of Table III further reveals that nitromethane does not in general quench the fluorescence emission of nonalternant PAHs. For 9 of the 13 nonalternant PAHs studied, the corrected fluorescence emission intensity remained essentially constant, at least to within $\pm 10 \%$. Addition of nitromethane to several of the solutions initially increased $F^{c o r r}$, perhaps because $f_{\text {prim }}$ was calculated on the basis of an incorrectly assumed sample cell configuration or, more likely, because nitromethane helped re-dissolve the small amount of PAH which was still adsorbed onto the test tube or cuvette walls. Benzo[k]fluoranthene, fluoranthene, and naphtho$[2,3 \mathrm{~b}]$ fluoranthene are the only three exceptions to the nitromethane selective quenching observation that we found, though naphtho[1,2b]fluoranthene might be considered by some researchers as a "borderline case," since its fluorescence intensity did drop by more than $20 \%$, even after the primary inner-filtering corrections were made. Secondary inner-filtering corrections were not necessary in the present study. Nitromethane does not absorb appreciable radiation in these PAH's emission ranges. Quenching of benzo[k]fluoranthene and fluoranthene fluorescence emission by nitromethane confirms the earlier contentions of Dreeskamp et al. ${ }^{16}$ that these two nonalternant PAHs are indeed exceptions. Additional measurements are currently underway to further study the effect of nitromethane, nitrobenzene, and 1,2,4trimethoxybenzene on the fluorescence emission behavior of both alternant and nonalternant polycyclic aromatic hydrocarbons to determine whether previously reported selective quenching observations ${ }^{14-18}$ still hold after all inner-filtering corrections are taken into account.

\section{ACKNOWLEDGMENTS}

This work was supported in part by a grant from the National Science Foundation (Grant No. CTS-8922485), by the University of North Texas Research Council, and by a National Science Foundation Doctoral Research Fellowship awarded to S. A. Tucker. The authors also acknowledge support from the National Institute of Environmental Health Sciences (Grant No. ES-04266).

1. R. Waris, M. A. Rembert, D. M. Sellers, W. E. Acree, Jr., K. W. Street, Jr., C. F. Poole, P. H. Shetty, and J. C. Fetzer, Appl. Spectrosc. 42, 1525 (1988). 
2. R. Waris, M. A. Rembert, D. M. Sellers, W. E. Acree, Jr., K. W. Street, Jr., and J. C. Fetzer, Analyst 114, 195 (1989).

3. R. Waris, W. E. Acree, Jr., K. W. Street, Jr., and J. C. Fetzer, Appl. Spectrosc. 43, 845 (1989).

4. W. E. Acree, Jr., S. A. Tucker, A. I. Zvaigzne, K. W. Street, Jr., J. C. Fetzer, and H.-F. Grutzmacher, Appl. Spectrosc. 44, 477 (1990).

5. W. E. Acree, Jr., S. A. Tucker, L. E. Cretella, A. I. Zvaigzne, K. W. Street, Jr., J. C. Fetzer, K. Nakasuji, and I. Murata, Appl. Spectrosc. 44, 951 (1990).

6. S. A. Tucker, A. I. Zvaigzne, W. E. Acree, Jr., J. C. Fetzer, and M. Zander, Appl. Spectrosc. 45, 424 (1991).

7. W. E. Acree, Jr., S. A. Tucker, and J. C. Fetzer, Polycyclic Aromatic Compounds, in press.

8. T. L. Cecil and S. C. Rutan, Anal. Chem. 62, 1998 (1990).

9. J. R. Lakowicz, Principles of Fluorescence Spectroscopy (Plenum Press, New York, 1983).

10. R. E. Kalman, J. Basic Eng. 82, 34 (1960).

11. S. C. Rutan, J. Chemom. 1, 7 (1987).

12. S. D. Brown, Anal. Chim. Acta 181, 1 (1986).
13. S. C. Rutan, D. D. Gerow, and G. Hartman, Intell. Lab. Sys. 3, 61 (1988).

14. E. Sawicki, T. W. Stanley, and W. C. Elbert, Talanta 11, 1433 (1964).

15. G.-P. Blümer and M. Zander, Fresenius Z. Anal. Chem. 296, 409 (1979).

16. H. Dreeskamp, E. Koch, and M. Zander, Z. Naturforsch. 30A, 1311 (1975).

17. M. Zander, U. Breymann, H. Dreeskamp, and E. Koch, Z. Naturforsch. 32A, 1561 (1977).

18. U. Breymann, H. Dreeskamp, E. Koch, and M. Zander, Chem. Phys. Lett. 59, 68 (1978)

19. B. P. Cho and R. G. Harvey, J. Org. Chem. 52, 5668 (1987).

20. D. C. Dong and M. A. Winnick, Can. J. Chem. 62, 2560 (1984).

21. C. A. Parker and W. J. Barnes, Analyst 82, 606 (1957).

22. J. F. Holland, R. E. Teets, P. M. Kelly, and A. Timnick, Anal. Chem. 49, 706 (1977).

23. M. C. Yappert and J. D. Ingle, Appl. Spectrosc. 43, 759 (1989). 